\title{
Super Light Car-lightweight construction thanks to a multi-material design and function integration
}

\author{
Martin Goede • Marc Stehlin • Lukas Rafflenbeul • \\ Gundolf Kopp • Elmar Beeh
}

Received: 2 October 2008 / Accepted: 5 November 2008 / Published online: 26 November 2008

(C) European Conference of Transport Research Institutes (ECTRI) 2008

\begin{abstract}
The Super Light Car (SLC) project is one of the most important research projects in the European Community for automotive lightweight construction with a multimaterial approach. The paper shows the motivation and objectives for a front structure designed with a light multimaterial-mix.
\end{abstract}

Keywords Super Light Car · Automotive lightweight construction $\cdot$ Multi-material structures

\section{Motivation and challenge}

Global warming is a fact. One of the main reasons are the $\mathrm{CO}_{2}$ emissions (23\%) being caused by the vehicle traffic. In 2005, this corresponded to approx. 6 billion metric tons of $\mathrm{CO}_{2}$ [1]. Without conducting an evaluation showing in detail how these emissions affect global warming, it can be said that the political pressure to reduce these emissions from vehicle traffic is increasing.

As a result, several approaches have already been accomplished by the automotive industry. The reduction in consumption and emissions remains the greatest technological challenge for the automotive industry $[2,3]$. The

M. Goede $\cdot$ M. Stehlin $(\bowtie) \cdot$ L. Rafflenbeul

Volkswagen AG,

Konzernforschung,

Wolfsburg, Germany

e-mail: marc.stehlin@volkswagen.de

G. Kopp · E. Beeh

Institut für Fahrzeugkonzepte,

Deutsches Zentrum für Luft- und Raumfahrt e.V.,

Stuttgart, Germany reduction in consumption required cannot be achieved through continual improvement of the drive chain and thus an increase in energy efficiency alone. The path of reducing driving resistances, especially vehicle weight, must also be followed. Vehicle mass affects the energy consumption of the vehicle through mass-related driving resistances.

Reducing weight by $100 \mathrm{~kg}$ leads to a fuel savings of $0.35 \mathrm{l} / 100 \mathrm{~km}$ and $8.4 \mathrm{~g} \mathrm{CO}_{2} / \mathrm{km}$ with gasoline engines in the NEDC if taking into account an adjustment of the gear shifting without a change in elasticity and acceleration values due to the lower weight [4].

\section{Super Light Car (SLC) EU project}

The "Super Light Car" (SLC) EU-project started at the beginning of 2005 with the motivation to reduce weight in vehicle bodies through the economically feasible production of multi-material structures (Figs. 1 and 2) which would contribute to a reduction of consumption and $\mathrm{CO}_{2}$ in the automobile. One of the objectives in the project is to reduce the weight in the body in white (B.I.W.) by at least $30 \%$ (reference: A-class segment unibody structure) through a lightweight construction for volume production of 1,000 vehicles per day. This should be achieved under consideration of various vehicle-specific requirements, e.g. high crash safety and stiffness.

A series of goal conflicts which need to be analysed and assessed results from these goals and requirements. The task of the 37 project partners was to find the best possible solution with regard to lightweight construction and the specified requirements. In addition to lightweight construction, issues such as economic viability and reliable manufacturing processes for individual structures, assemblies and the body are examined here. Today, lightweight 


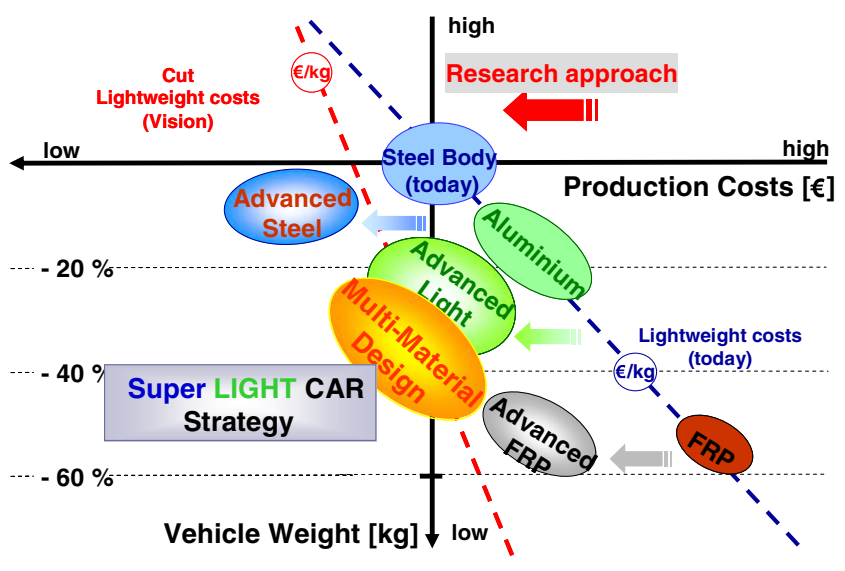

Fig. 1 Multi-Material-Design Research Approach

construction can not longer be achieved through materials alone. Appropriate construction principles, manufacturing and joining technologies must also be considered as focal points in multi-material design. Approaches to a solution show positive trends toward lighter vehicle concepts, but must be continually scrutinised with regard to the recycling requirements. These problems were examined in the SLC project by various project partners from the industry and research fields.

The Institute of Vehicle Concepts (DLR) designed, constructed and simulated a front end module with magnesium and aluminium structural components in the EU project. This concept was created building upon a methodical analysis of the reference structure and resulted in a weight reduction of $24 \mathrm{~kg}$ through justifiable additional costs and fulfilment of the requirements, e.g. crash and stiffness. These technological results lead the SLC consortium to select this concept as the prototype.

Before this decision could be made, a host of various design concepts were developed in the "Design Concepts" subproject. This work included the construction, simula- tion, evaluation and optimisation of the individual structures in the front end. Design of the front end, floor and structural modules was carried out under the direction of Volkswagen AG, which was in charge of overall coordination of the SLC project. These modules were optimised in three different development threads with respect to the overall SLC body design. The three threads, "steel intensive", "Multi material, economic" and "Multi material, advanced", had different aims during development with regard to weight reduction and the additional costs involved in lightweight construction in comparison to the benchmark vehicle. The specifications for weight achieved a reduction from 10 to 25 to $45 \%$.

Concept development was supported and supplemented by the "Materials \& Manufacturing Technologies" and "Simulation \& Testing" subprojects, in which the required technologies for economic multi-material lightweight construction were developed. In addition, the costs and LCA (Life Cycle Assessment) were taken into account during concept development. The SLC body concept will finally be presented as a prototype for physical testing and subsequently validated in the fourth subproject at the beginning of 2009 .

\section{Front end concept}

With the front end concept, the challenge was to reduce the weight of a $76 \mathrm{~kg}$ module using a variety of lightweight materials in the optimum places. To proceed methodically, the front end area of the mostly-steel benchmark structure was analysed with regard to the materials used, production methods and component costs and their requirements when the work was begun. Preliminary conceptual considerations for lighter front end structures were made while taking into account aluminium alloy casting, the assembly of parts and the integration of functions.
Fig. 2 Approach and schedule of SLC

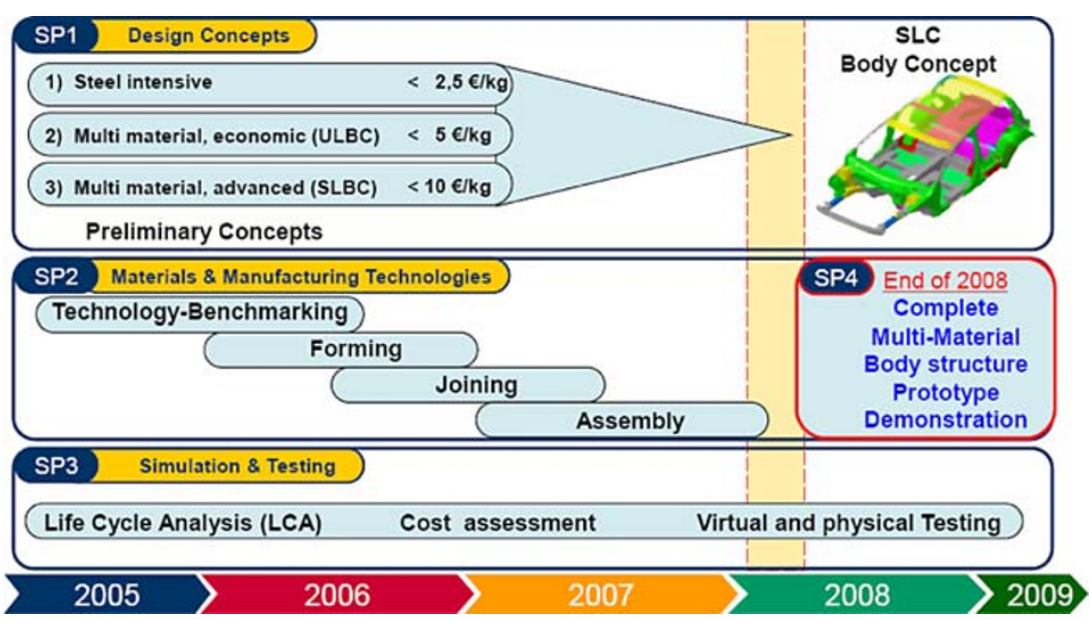


Fig. 3 Example of benchmark structure parts and part list





Using the parts list of the reference structure, Fig. 3, components suitable for integration into a single cast part due to their arrangement, function and specific costs were identified.

In taking these elements into account, the conceptual idea of combining the area of the top longitudinal rail, the strut tower and the engine and transmission mount into a single large aluminium alloy cast component was developed. This area has stringent requirements regarding crash safety of the vehicle, e.g. in case of a head-on collision, and the torsion and flexural stiffness of the entire vehicle structure.

In previous vehicles, these requirements were fulfilled using sheet metal or cast metal solutions made of steel or aluminum. As a result of the goals for weight reduction, the engineers aimed at a solution using magnesium casting despite the great challenges involved. This would involve unique new technologies for the use of magnesium in loadbearing structures. Sheet aluminium was identified as an ideal solution for the adjoining areas and the rest of the front end, Fig. 4.

Detail development took place over several development loops between construction (CATIA V5) and simulation



Fig. 4 DLR front end concept with magnesium cast strut tower (yellow) and aluminium structures (green)
(LS-Dyna). The optimisation of crash behaviour of the multi-material structure, in particular, required more than 80 overall vehicle crash calculations.

First, the crash behaviour of the magnesium component was optimised for the $\mathrm{OBD}^{1}$ crash load case (Figs. 5 and 6). Through precise analysis of the calculated component failure, the component was improved geometrically and with regard to wall thickness distribution. To reproduce the material properties of the selected magnesium alloy AM50 as realistically as possible, material failures with a breakage elongation of $8 \%$ were computed in the crash simulation. In addition, great importance was attached from the very beginning to the manufacturing capability using the die-cast process. In the second stage of development, the surrounding steel structure was replaced with a lighter aluminium structure. This structure was then also optimised for advantageous crash behaviour in the overall vehicle structure. The force-displacement diagrams, intrusions, compare Fig. 7 and the simulation films of every design variant were analysed. The geometry, wall thickness or material changes of every new variant was examined to determine what benefits they could offer. This allowed the longitudinal rail structure to be better utilised with regard to specific energy absorption and thus lightened in comparison to the respective reference structure.

Despite a reduction in weight of $32 \%$ in the front end, excellent crash behaviour was achieved. In several areas, the crash behaviour was actually improved in comparison to the reference structure. For example, the footwell intrusion measurement of $51 \mathrm{~mm}$ of the DLR concept is clearly an improvement over the $100 \mathrm{~mm}$ of the reference structure.

By reducing the weight of the front end by $24 \mathrm{~kg}$, the set project goal of more than $30 \%$ was reached. The highlyintegrated magnesium cast component described above, which combines some 12 steel components into a single cast component and reduces the weight by more than $60 \%$, was responsible for a considerable portion of this.

\footnotetext{
${ }^{0}$ ODB — Offset Deformable Barrier
} 




Fig. 5 ODB crash of the SLC vehicle

Fig. 6 Analyse of the plastic strain of the reference (right) and SLC concept (left)


Fig. 7 Intrusion analyses of the SLC concept

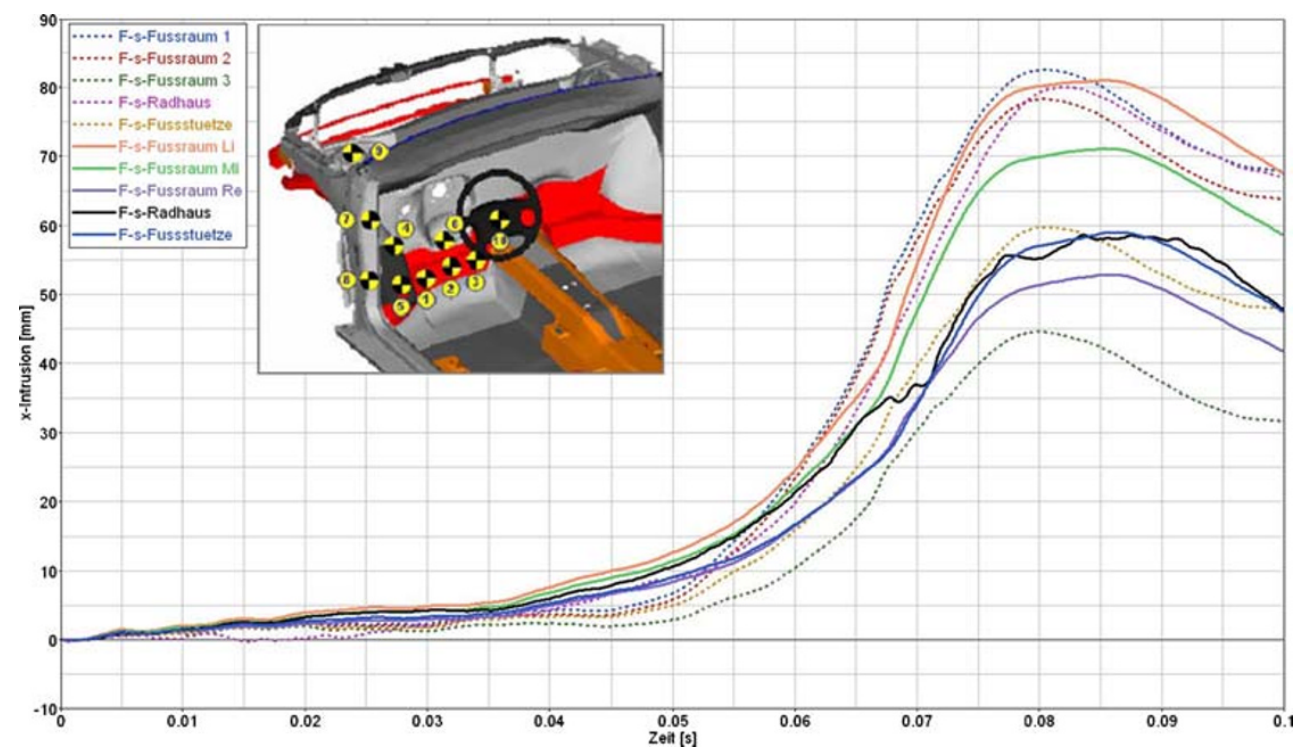




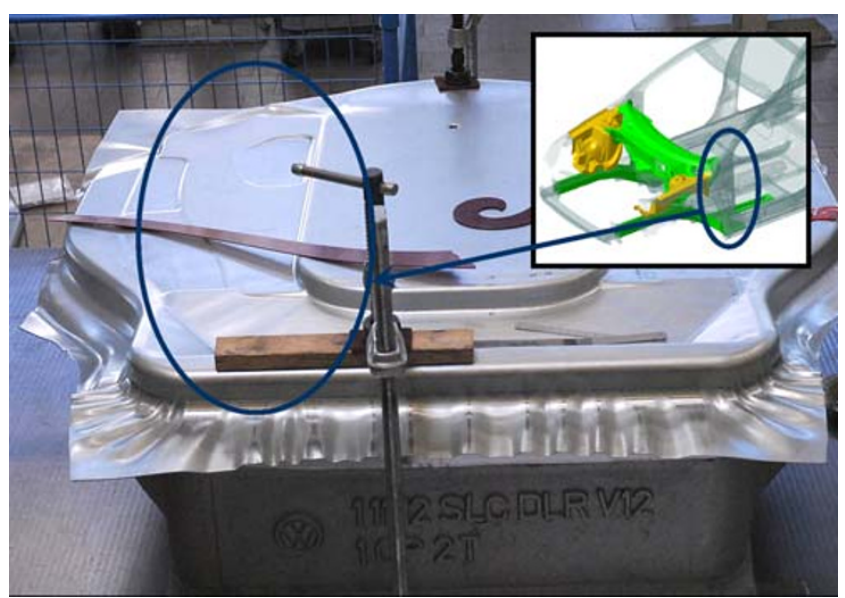

Fig. 8 Representation of an A-Pillar component in prototyping by Volkswagen AG

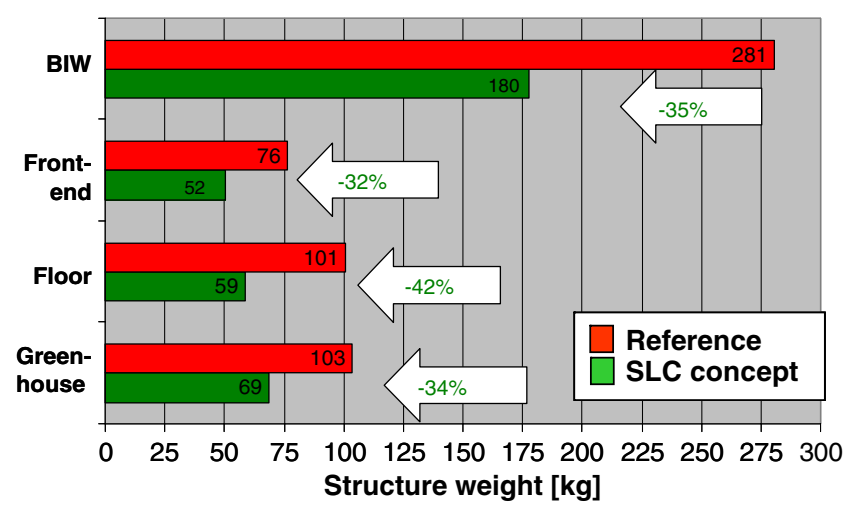

Fig. 9 Result of SLC

\section{Conclusion and outlook}

The results for the strut mounting show a part weight of $2.8 \mathrm{~kg}$ and thus a weight reduction of up to $4.9 \mathrm{~kg}$ (Fig. 8). The great reduction in weight results firstly from the lightweight construction concept, in which functions and parts were integrated into a highly-integrated cast component, secondly from the lightweight materials, i.e. the use of magnesium, and finally from the lightweight layout and the resulting geometric optimisation. It should be mentioned that the concept could also be manufactured using aluminium casting exhibiting similar wall strength, however the reduction in weight would not be as great in comparison to magnesium. Simulation results show that all specified static and dynamic load cases are satisfied. These results lead to the decision that this concept would be examined further, and testing of the results of simulations in real trials is made possible through the creation of prototypes for everything from individual structures to the entire vehicle body.

Upon completion of this extensive 4-year project involving 37 partners, a multi-material lightweight construction vehicle body with a $35 \%$ reduction in weight will be presented in February 2009 (Fig. 9).

Material, design and manufacturing technologies remain key technologies in vehicle development. Only integrated approaches that work on these three key technologies will be successful in the future. In addition to the development of metals and light metals, the research on fibre-reinforced plastics will play a major role. In the area of joining technologies mechanical joining, adhesive and hybrid methods will complement to approve welding technologies (Fig. 10).

In addition to the vehicle body, systematic lightweight design concepts will integrate equipment, chassis, engine and electronics. Sustainable concepts which benefit from
Fig. 10 Main challenge in body design: the multi material concepts [5]

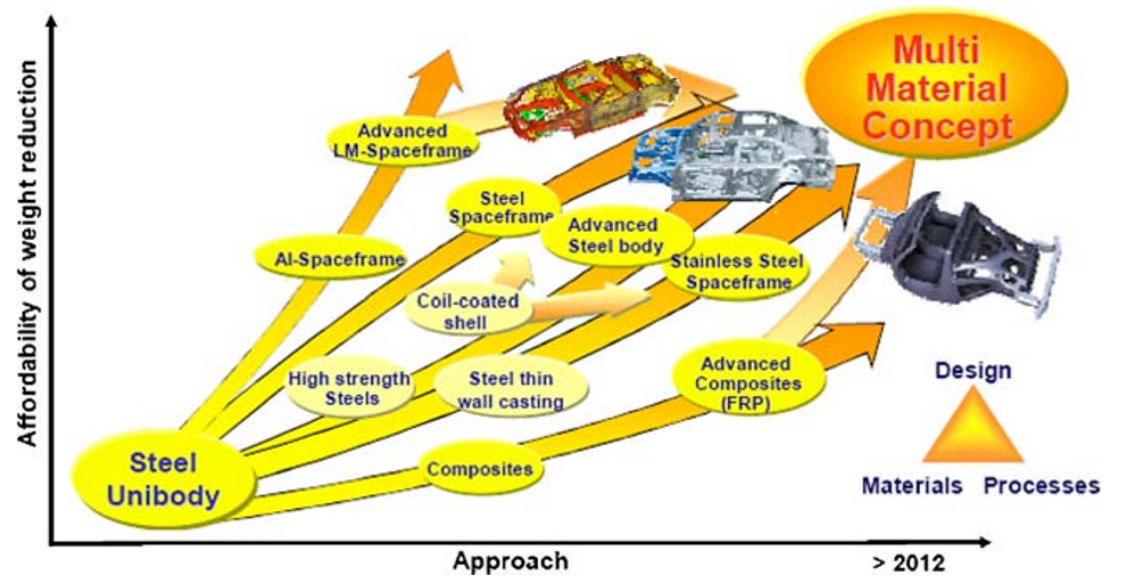


secondary lightweight effects will play a decisive role in future car design.

\section{References}

1. Goede M (2006) Super light car: Sustainable production technologies of emission reduced light weight car concepts (SLC). Transport Research Arena Europe 2006. June 12th-15th 2006, Göteborg, Sweden
2. Goede $\mathrm{M}$ (2007) Karosserieleichtbau als Baustein einer $\mathrm{CO}_{2}$ Reduzierungsstrategie; Aachener Kolloquium, Fahrzeug- und Motorentechnik; Aachen; 8.-11. Oktober

3. Seiffert U (2002) Die Bedeutung des Leichtbaus im Fahrzeugbau. Clausthal, 2002, Industrie-Kolloquium, 6./7.2

4. Winterkorn M., Ludanek H., Rohde-Brandenburger K (2008) $\mathrm{CO}_{2}-$ Reduzierungspotential durch Leichtbau und der Automobilindustrie, Dresdner Leichtbausymposium, Dresden, 12.6

5. World Business Council for Sustainable Development: The Sustainable Mobility Project-Full Report 2004, p. 37 